Oski, FA (eds) Hematology of Infancy and Childhood, 2nd ed. WB Saunders Company, London, p. 513

28. Mentzer WC, Turetsky T, Mohandas N, Koenig H, Schrier S 1982 Identification of the hereditary pyropoikilocytosis (HPP) carrier state. Blood 60:38a (Suppl 1, abstr)

29. Morrissey DH 1981 Silver stain for proteins in polyacrylamide gels: a modified procedure with enhanced uniform sensitivity. Anal Biochem 117:307

30. Morrow JS, Marchesi VT 1981 Self-assembly of spectrin oligomers in vitro: a basis for a dynamic cytoskeleton. J Cell Biol 88:463

31. Morrow JS, Speicher DW, Knowles WJ, Hsu CJ, Marchesi VT 1980 Identification of functional domains of human erythrocyte spectrin. Proc Natl Acad Sci USA 77:6592

32. Nielsen JA, Strunk KW 1968 Homozygous hereditary elliptocytosis as the cause of haemolytic anemia in infancy. Scand J Haematol 5:486

33. Palek J, Lux SE 1983 Red cell membrane skeletal defects in hereditary and acquired hemolytic anemias. Semin Hematol 20:189

34. Prchal JT, Castleberry RP, Parmley RI, Crist WM, Mulluh A 1982 Hereditary pyropoikilocytosis and elliptocytosis: clinical, laboratory and ultrastructural features in infants and children. Pediatr Res 16:484

35. Pryor DS, Pitney WR 1967 Hereditary elliptocytosis: a report of two families from New Guinea. Br J Haematol 13:126

36. Speicher DW, Morrow JS, Knowles WJ, Marchesi VT 1982 A structural model of human erythrocyte spectrin: alignment of chemical and functional domains. J Biol Chem 257:9093

37. Tchernia G, Mohandas N, Shohet SB 1981 Deficiency of skeletal membrane protein band 4.1 in homozygous hereditary elliptocytosis. Implications for erythrocyte membrane stability. J Clin Invest 68:454

38. Torlontano G, Fioritoni G, Salvati AM 1979 Hereditary haemolytic ovalocytosis with defective erythropoiesis. Br J Haematol 43:435

39. Ungewickell E, Bennett PM, Calvert R, Ohanian V, Gratzer WB 1979 In vitro formation of a complex between cytoskeletal proteins of the human erythrocyte. Nature 80:811

40. Weiss HJ 1963 Hereditary elliptocytosis with hemolytic anemia. Report of six cases. Am J Med 35:455

41. Wyanot H, Bancroft PM, Winship TO 1941 Elliptic erythrocytes in man. Arch Intern Med 68:1043

42. Zarkowsky HS, Mohandas N, Speaker CB, Shohet SB 1975 A congenital haemolytic anaemia with thermal sensitivity of the erythrocyte membrane. Br J Haematol 29:537

\title{
Iron Is Sequestered as Ferritin in Macrophages in Skeletal Muscle of Vitamin E-deficient Rabbits
}

\author{
JEN-YIH CHU, PHITSAMAI KANJANANGGULPAN, ALBERT C. CHOU,' \\ DAPHNE E. DE MELLO, AND COY D. FITCH \\ Departments of Pediatrics, Pathology, and Internal Medicine, St. Louis University School of Medicine, \\ St. Louis, Missouri, 63104
}

\section{Summary}

Weanling rabbits were fed a purified diet with or without vitamin $\mathrm{E}$ supplementation to evaluate the abnormal sequestration of iron in skeletal muscle associated with vitamin $\mathbf{E}$ deficiency. A severe myopathy developed in unsupplemented rabbits within 3 to 4 weeks. At this time, the concentration of soluble nonheme iron in biceps femoris muscles had increased from 2.1 $\pm 0.4 \mu \mathrm{g} / \mathrm{g}$ wet weight (mean $\pm \mathrm{SD}$ ) for six control rabbits to 4.3 \pm 1.4 for 10 vitamin E-deficient rabbits, and total nonheme iron had increased from $5.0 \pm 1.2$ to $8.4 \pm 3.3$. Soleus muscles had even greater increases in total and soluble nonheme iron concentrations. Intramuscular injection of iron-dextran caused large increases in total and soluble nonheme iron in noninjected muscle of vitamin E-deficient rabbits, which further exaggerated the difference between the two groups. By radioimmunoassay using an antibody to rabbit liver ferritin, the concentration of ferritin in biceps femoris muscles increased from $0.47 \pm 0.18 \mu \mathrm{g} / \mathrm{g}$ wet weight for seven control rabbits to $6.34 \pm 1.70$ for 14 vitamin $\mathrm{E}$ -

Received February I, 1984; accepted March 26, 1984.

Requests for reprints should be addressed to Jen-Yih Chu, M.D., Department of Pediatrics, Cardinal Glennon Memorial Hospital for Children, 1465 S. Grand, St. Louis, MO 63104

This research was supported in part by Grant 82-CRCR-1-1114 from the Human Nutrition Program, Science and Education Administration, United States Department of Agriculture and in part by a Biomedical Research Support Grant from the School of Public Health and Tropical Medicine, Tulane University and Fleur de Lis Fund, Cardinal Glennon Memorial Hospital for Children. We wish to thank Judith Baldassare, Mary Ann Collins, Alice Cottrell, and Mary McGlone for their technical help and Merrell Dow Pharmaceuticals, Inc., Cincinnati, for the supply of iron dextran used in this study.

Present address: Department of Nutrition, Tulane University School of Public Health and Tropical Medicine, New Orleans, LA 70112 deficient rabbits. Uptake of intravenously injected transferrinbound iron into muscle of vitamin E-deficient rabbits was not increased in a short term experiment $(6 \mathrm{~h})$, but radioiron did accumulate in muscle in a long term experiment (6 days). There was no trapping of heat-damaged erythrocytes, no phagocytosis of intravenously injected carbon particles, and no erythrophagocytosis in muscle. An immunohistological staining method designed to detect ferritin in tissue sections stained muscle from normal rabbits very scantily but intensely stained macrophages in the muscle of vitamin E-deficient rabbits. We conclude that macrophages in skeletal muscle of vitamin E-deficient rabbits take up iron from transferrin and incorporate it into ferritin, in which form it is relatively unavailable for erythropoiesis because of slow release.

Young vitamin E-deficient rabbits have high serum ironbinding capacity, low serum iron, and high erythrocyte free protoporphyrin concentrations, and they recover slowly from anemia induced by phlebotomy (2). These abnormalities are secondary to iron sequestration in muscle rather than to a decrease in the total amount of iron in the body (2). Since vitamin E-deficiency is known to cause an extensive necrotizing myopathy accompanied by infiltration of macrophages (1), the present study evaluated the involvement of macrophages in the sequestration of iron.

\section{MATERIALS AND METHODS}

Young New Zealand White rabbits initially weighing approximately $650 \mathrm{~g}$ were used in all except one experiment. Rabbits 
weighing approximately $1200 \mathrm{~g}$ were used in that experiment to ensure longer survival. All of the rabbits were fed a purified, vitamin E-deficient diet developed by Young and Dinning (16) and modified by Diehl (6). On a dry weight basis, it contains $11.3 \%$ casein, $29.5 \%$ sucrose, $27 \%$ cornstarch, $25 \%$ cellulose, $2.25 \%$ cod liver oil, $2.25 \%$ lard stripped of vitamin E, and all of the essential minerals and vitamins except vitamin E. Control rabbits received the same diet plus an oral supplement of $8 \mathrm{mg}$ of $d$ - $\alpha$-tocopheryl acetate in $0.2 \mathrm{ml}$ of corn oil 3 times/week. Food and water were supplied ad libitum. For 5 days of each week, the water contained $0.04 \%$ sulfaquinoxaline (Ralston Purina Company, St. Louis) as prophylaxis against coccidiosis.

In certain of the experiments, control and vitamin E-deficient rabbits received extra iron as iron-dextran (Imferon, Merrell Dow Pharmaceuticals, Inc., Cincinnati) intramuscularly. In still other experiments, some of the rabbits were used to determine the effect of short term vitamin E repletion on iron concentrations in skeletal muscle. For this purpose, four rabbits each received $40 \mathrm{mg}$ of $d$ - $\alpha$-tocopheryl acetate dissolved in $1.0 \mathrm{ml}$ of corn oil by mouth daily when they developed the signs of severe vitamin E deficiency. Immediately prior to and 3 days after initiating vitamin $E$ treatment, blood was obtained and a soleus muscle was removed surgically for iron measurements.

Sodium pentobarbital plus ether or ketamine plus xylazine were used for anesthesia to obtain blood and tissue samples. While anesthetized, the rabbits were killed by exsanguination.

Assessment of vitamin $E$ deficiency. Measurements of body weight, serum tocopherol concentration (12), susceptibility of erythrocytes to hemolysis by hydrogen peroxide (8), creatinuria (7), and serum iron (11) and iron binding capacity (3) were used to assess the severity of vitamin E deficiency. Shown in Table 1 are data obtained just prior to or at the time tissue samples were obtained for iron and ferritin measurements, which was approximately 3 weeks after beginning the purified diet. The vitamin E-deficient rabbits gained weight slowly, and they had low serum vitamin E concentrations, erythrocytes highly susceptible to hydrogen peroxide hemolysis, creatinuria, low serum iron, and high serum total iron binding capacity. In addition, extreme weakness was apparent when the vitamin E-deficient rabbits attempted to right themselves after being placed on their sides. If not killed at this point in time, these small rabbits invariably died within a week. The same assessment of the larger rabbits yielded similar evidence of vitamin $\mathrm{E}$ deficiency 4 to 5 weeks after beginning the purified diet. However, most of the larger rabbits survived for a week or more after they developed severe myopathy.

Iron and ferritin measurements. The serum iron concentration was measured according to the recommendation of the International Committee for Standardization in Hematology (11), and the serum total iron binding capacity was measured by the light magnesium carbonate method (3). Nonheme iron in tissue homogenates was measured by the method of Torrance and Bothwell (14). To measure the soluble fraction of nonheme iron in tissues, the specimens were homogenized in water in ground glass tubes with tightly fitted ground glass pestles and centrifuged at $4^{\circ} \mathrm{C}$ and $12,000 \times \mathrm{g}$ for $70 \mathrm{~min}$. The supernatant solutions

Table 1. Comparison of control and vitamin E-deficient rabbits

\begin{tabular}{lcc}
\hline & Control & $\begin{array}{c}\text { Vitamin E- } \\
\text { deficient }\end{array}$ \\
\hline Initial body weight $(\mathrm{g})$ & $665 \pm 142(10)^{*}$ & $630 \pm 153(13)$ \\
Final body weight $(\mathrm{g})$ & $901 \pm 127(10)$ & $690 \pm 125(13) \dagger$ \\
Hydrogen peroxide hemolysis $(\%)$ & $1.3 \pm 2.6(10)$ & $96.0 \pm 3.2(11) \dagger$ \\
Serum vitamin E $(\mu \mathrm{g} / \mathrm{dl})$ & $639 \pm 212(10)$ & $45 \pm 15(11) \dagger$ \\
Urinary creatine $\ddagger$ & $0.13 \pm 0.08(6)$ & $4.3 \pm 2.1(12) \dagger$ \\
Serum iron concentration $(\mu \mathrm{g} / \mathrm{dl})$ & $221 \pm 24(10)$ & $174 \pm 69(12) \dagger$ \\
Iron binding capacity $(\mu \mathrm{g} / \mathrm{dl})$ & $246 \pm 14(10)$ & $359 \pm 47(12) \dagger$ \\
\hline
\end{tabular}

* Mean \pm SD. The numbers in parentheses are the numbers of rabbits.

$\dagger p<0.05$ by Student's $t$ test.

$\ddagger$ Expressed as a molar ratio to urinary creatinine. then were transferred to other tubes and centrifuged again under similar conditions to remove particulate material before measuring nonheme iron (14).

For measurements of ferritin concentrations, tissue homogenates were centrifuged at $4^{\circ} \mathrm{C}$ and $1500 \times g$ for 20 min to obtain a supernatant solution for analysis. Ferritin was measured by standard radioimmunoassay methods (10) using ${ }^{125}$ I-labeled rabbit liver ferritin, guinea pig antiferritin antibodies to complex the ferritin, and an excess of rabbit anti-guinea pig Immunobeads (Bio-Rad Laboratories; antigen capacity, $3.75 \mu \mathrm{g} / \mathrm{mg}$ beads) to precipitate the ferritin-antiferritin complexes for counting. Rabbit liver ferritin was purified from healthy adult rabbits after repeated injections of iron-dextran as described by Penders et al. (13) for use as a standard and as the antigen for production of antiferritin antibodies and for labeling with ${ }^{125} \mathrm{I}$ by the chloramine T method (9).

Antiferritin antibodies were raised in each of four adult guinea pigs by giving an initial subcutaneous injection of $600 \mu \mathrm{g}$ of the purified ferritin dissolved in $0.5 \mathrm{ml}$ of $0.25 \mathrm{M}$ phosphate buffer ( $\mathrm{pH} 7.2$ ) mixed with $0.5 \mathrm{ml}$ of Freund's complete adjuvant. At weekly intervals thereafter, three booster doses of $600 \mu \mathrm{g}$ ferritin mixed with $0.5 \mathrm{ml}$ of Freund's incomplete adjuvant were given. The guinea pigs were bled by cardiac puncture under anesthesia 6 weeks after the initial ferritin injection, their sera (approximately $3 \mathrm{ml}$ from each) were pooled, and a partially purified antibody fraction was prepared as follows. The pooled sera were mixed with an equal volume of borate-saline medium $(8.37 \mathrm{~g}$ boric acid, $6.19 \mathrm{~g}$ sodium borate, and $9.38 \mathrm{~g} \mathrm{NaCl}$ per liter, $\mathrm{pH}$ 8.02 ), after which protein was precipitated by slowly adding solid $\mathrm{Na}_{2} \mathrm{SO}_{4}$ to a final concentration of $18 \%$. The precipitate was collected by centrifugation and washed once with $18 \% \quad \mathrm{Na}_{2} \mathrm{SO}_{4}$ dissolved in the borate-saline medium. Then, the precipitate was dissolved in a minimum volume of borate-saline medium. Removal of $\mathrm{Na}_{2} \mathrm{SO}_{4}$ was accomplished by Sephadex G-25 column chromatography and dialysis overnight in borate-saline medium. By Ouchterlony double diffusion immunoassay (10), this antibody preparation gave precipitation lines indicating reactions of identity with purified rabbit liver ferritin and the ferritin in crude soluble preparations of liver, spleen, and skeletal muscle from vitamin E-deficient rabbits. A concentration of antibody approximately equivalent to a 1:100,000 dilution of the original serum pool was used for the radioimmunoassays.

Radiotracer studies. To evaluate the tissue distribution of radioiron bound to transferrin, $9 \mathrm{ml}$ of blood was obtained from vitamin E-deficient or control donor rabbits and mixed with 1 $\mathrm{ml}$ of acid-citrate-dextrose solution ( $7.3 \mathrm{~g}$ citric acid, $22 \mathrm{~g}$ sodium citrate, and $24.5 \mathrm{~g}$ dextrose per liter). The erythrocytes were removed by centrifugation and $4 \mathrm{ml}$ of plasma was incubated for $60 \mathrm{~min}$ at room temperature with $88 \mu \mathrm{Ci}$ of ${ }^{59} \mathrm{Fe}$ (ferrous citrate, $25 \mu \mathrm{Ci} / \mathrm{ml} ; 13-16 \mathrm{mCi} / \mathrm{mg}$ iron). The labeled plasma then was injected intravenously $(0.6 \mathrm{ml} / \mathrm{kg}$ body weight $)$ through an ear vein into control and severely vitamin E-deficient rabbits. Control rabbits received plasma from a control donor and vitamin E-deficient rabbits received plasma from a vitamin E-deficient donor. Radioiron distribution was measured either $6 \mathrm{~h}$ or 6 days later by killing the rabbits and removing and mincing selected tissues for counting in a gamma counter. Because of variations in radioactivity in various muscles, all of the muscles of one thigh were pooled for use as a single sample.

Heat damaged ${ }^{51} \mathrm{Cr}$-labeled erythrocytes were used to explore the possibility of erythrocyte sequestration in skeletal muscle of vitamin E-deficient rabbits. Blood $(9 \mathrm{ml})$ was collected from a control donor rabbit, mixed with $1 \mathrm{ml}$ of acid-citrate-dextrose solution and $1 \mathrm{ml}$ of ${ }^{51} \mathrm{Cr}(105 \mu \mathrm{Ci} / \mathrm{ml}, 50 \mathrm{mCi} / \mathrm{mg}$ sodium chromate), and incubated for $30 \mathrm{~min}$ at room temperature. The mixture next was incubated in a water bath at $49^{\circ} \mathrm{C}$ for $10 \mathrm{~min}$ to damage the erythrocytes. Then the erythrocytes were collected by centrifugation, washed twice with 2 volumes of $0.9 \% \mathrm{NaCl}$, and resuspended in an equal volume of $0.9 \% \mathrm{NaCl}$ for intravenous injection. Control and vitamin E-deficient rabbits each received $1 \mathrm{ml}$ of this preparation of erythrocytes per $\mathrm{kg}$ of body 
Table 2. Nonheme iron in various tissues

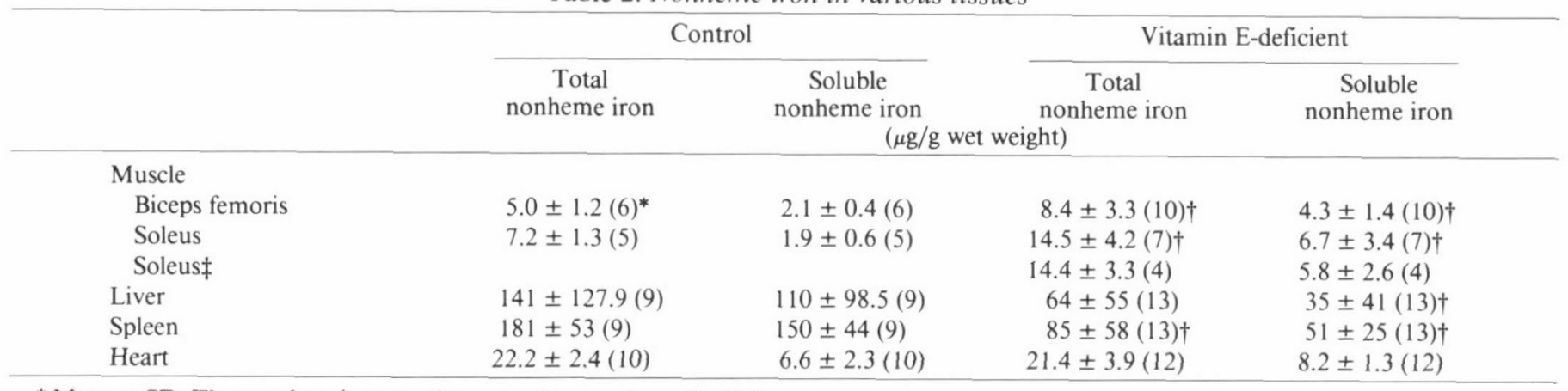

* Mean \pm SD. The numbers in parentheses are the numbers of rabbits.

$\dagger p<0.05$ in comparisons between control and vitamin E-deficient rabbits using Student's $t$ test.

$\ddagger$ After treatment with $40 \mathrm{mg}$ of $d$ - $\alpha$-tocopheryl acetate daily for 3 days.

weight. The rabbits were killed $21 \mathrm{~h}$ later and selected tissues were removed, minced, and counted in a gamma counter.

Histologic studies. Muscle specimens were fixed in $10 \%$ buffered formalin, embedded in paraffin, cut into $5-\mu \mathrm{m}$ specimens, and stained for iron with potassium ferricyanide and counterstained with nuclear fast red. For routine histology and evaluation of the uptake of colloidal carbon by macrophages, similar sections of muscle were stained with hematoxylin and eosin. To study the uptake of colloidal carbon, control and vitamin E-deficient rabbits were injected intravenously with 2.5 $\mathrm{ml} / \mathrm{kg}$ of body weight of black Pelikan drawing ink (No. 17, Pelikan AG, Hannover, Germany) which had been diluted with $0.9 \% \mathrm{NaCl}$ to achieve a carbon concentration of $60 \mathrm{mg} / \mathrm{ml}$ and centrifuged at $1000 \times g$ for $15 \mathrm{~min}$ to remove the larger aggregates. The rabbits were killed $3 \mathrm{~h}$ later to obtain muscle specimens.

For histochemical and immunohistological studies, muscle specimens were rapidly frozen in isopentane cooled to $-160^{\circ} \mathrm{C}$ with liquid nitrogen, and $6-\mu \mathrm{m}$ sections were cut in a cryostat and placed on microslides immediately. These sections were either studied immediately or stored at $-70^{\circ} \mathrm{C}$ until used. Some of the sections were stained for nonspecific esterase according to Yam et al. (15) using $\alpha$-naphthyl acetate as substrate. The remaining sections were used for the localization of ferritin by immunofluorescent staining.

For immunofluorescent staining, tissue sections on microslides were fixed in acetone for $5 \mathrm{~min}$, dried and covered with a dilute solution of the guinea pig antiferritin antibodies described above, and incubated in a moist chamber at room temperature for 30 $\min$. The antiferritin antibodies were prepared in phosphatebuffered saline $(0.9 \% \mathrm{NaCl}$ buffered to $\mathrm{pH} 7.2$ with $10 \mathrm{mM}$ phosphate) at a concentration approximately equivalent to a 1:160 or 1:320 dilution of the original serum pool. Serum from nonimmunized guinea pigs was used as the control. After incubation, the microslides were drained and washed twice with constant gentle agitation in a jar filled with phosphate-buffered saline for $15 \mathrm{~min}$ at room temperature. Then the sections were covered with fluorescein-tagged rabbit anti-guinea pig antibody (Miles-Yeda, Ltd., Elkhart, IN) and incubated for another 30 min at room temperature in a moist chamber, after which the excess fluorescein-tagged antibody was removed by washing twice with phosphate-buffered saline as before.

\section{RESULTS}

Iron and ferritin measurements. Nonheme iron concentrations in vitamin E-deficient rabbits increased in skeletal muscle, decreased in liver and spleen, and did not change in the heart (Table 2). In skeletal muscle, most of the increase occurred in the soluble fraction, which includes ferritin. To verify that ferritin concentrations in fact increased, a radioimmunoassay was ap-
Table 3. Ferritin by radioimmunoassay in muscle and liver

Control Vitamin E-deficient
( $\mu \mathrm{g} / \mathrm{g}$ wet weight)

$\begin{array}{lll}\text { Muscle } & & \\ \quad \text { Biceps femoris } & 0.47 \pm 0.18(7)^{*} & 6.34 \pm 1.70(14) \dagger \\ \text { Soleus } & 0.49 \pm 0.04(3) & 6.27 \pm 2.03(6) \dagger \\ \text { Liver } & 239 \pm 69(3) & 90 \pm 17.1(6) \dagger\end{array}$

* Mean \pm SD. The numbers in parentheses are the numbers of rabbits. $\dagger p<0.01$ by Student's $t$ test.

plied to biceps femoris muscles (Table 3). A smaller number of samples of soleus muscles and liver also were available for this assay. In each of these tissues from vitamin E-deficient rabbits, the change in ferritin concentration was in the direction predicted from measurements of nonheme iron. The relative increase in ferritin concentration in muscle was even greater than the increase in soluble nonheme iron.

Since the soleus, a red muscle, contained more iron (Table 2) and was more easily removed surgically than the biceps femoris muscle, it was used to study the effect of vitamin E treatment. No change in iron concentrations was detected after 3 days of treatment with large doses of $d$ - $\alpha$-tocopheryl acetate (Table 2) despite evidence of other physiological responses. For example, the serum iron concentration increased from $116.7 \pm 30$ to 176.3 $\pm 51.9 \mu \mathrm{g} / \mathrm{dl}$ (mean $\pm \mathrm{SD})$ in four rabbits, and hydrogen peroxide hemolysis decreased from 96 to $0.3 \%$ in the two rabbits tested.

The effect of treatment with extra iron also was studied. In a preliminary experiment, the serum iron concentrations 1 day after intramuscular injection of $25 \mathrm{mg}$ of iron as iron-dextran were $8748 \pm 766 \mu \mathrm{g} / \mathrm{dl}$ (mean $\pm \mathrm{SD})$ for five control rabbits and $4723 \pm 916 \mu \mathrm{g} / \mathrm{dl}$ for seven vitamin E-deficient rabbits. Some of the other effects of treatment with $25 \mathrm{mg}$ of intramuscular iron were evaluated in similar groups of rabbits in a subsequent experiment (Table 4). Six days after injection, more iron still remained in the injected muscle of vitamin E-deficient rabbits (the values ranged from 55 to $296 \mu \mathrm{g} / \mathrm{g}$ wet weight for three vitamin E-deficient rabbits and from 19 to $46 \mu \mathrm{g} / \mathrm{g}$ for six control rabbits). Nevertheless, parenteral iron treatment caused large increases in total and soluble nonheme iron in noninjected muscle of vitamin E-deficient rabbits, which further exaggerated the difference between the two groups. As in the untreated rabbits (Table 2), soleus muscles were more affected than biceps femoris muscles. After parenteral iron, the nonheme iron concentrations of liver and spleen of vitamin E-deficient rabbits approached the values achieved by control rabbits.

Radiotracer studies. Six hours after injecting transferrin-bound radioiron, a higher percentage of the injected dose was present in the bone marrow and a lower percentage was present in the liver of vitamin E-deficient than of control rabbits (Table 5). 
Table 4. Effect of iron treatment on nonheme iron in various tissues*

\begin{tabular}{cccc} 
& Control & & \multicolumn{2}{c}{ Vitamin E-deficient } \\
$\begin{array}{c}\text { Total } \\
\text { nonheme iron }\end{array}$ & $\begin{array}{c}\text { Soluble } \\
\text { nonheme iron }\end{array}$ & $\begin{array}{c}\text { Total } \\
\text { nonheme iron }\end{array}$ & $\begin{array}{c}\text { Soluble } \\
\text { nonheme iron }\end{array}$
\end{tabular}

$(\mu \mathrm{g} / \mathrm{g}$ wet weight)

$\begin{array}{lc}\text { Muscle } \dagger & \\ \text { Biceps femoris } & 6.6 \pm 0.9(6) \ddagger \\ \text { Soleus } & 17.5 \pm 3.0(6) \\ \text { Liver } & 369 \pm 64.3(6) \\ \text { Spleen } & 344 \pm 174(6) \\ \text { Heart } & 42.6+20.4(5)\end{array}$

$2.8 \pm 0.4(6)$
$6.0 \pm 2.7(6)$
$303 \pm 58.7(6)$
$251 \pm 159(6)$
$11.4 \pm 2.7(6)$

$11.5 \pm 4.6(3) \S$
$38.8 \pm 15.8(3) \S$
$340 \pm 128(3)$
$273 \pm 139(3)$
$38.7(2)$

$\begin{aligned} 7.8 & \pm 4.2(3) \S \\ 23.3 & \pm 12.0(3) \\ 267 & \pm 115(3) \\ 214 & \pm 95(3) \\ 10.8(2) & \end{aligned}$

* Iron $(25 \mathrm{mg})$ as iron-dextran was injected into the right thigh. The rabbits were killed and the various tissues were obtained 6 days after the iron injection.

$\dagger$ Muscles from the left thigh were analyzed.

$\ddagger$ Mean \pm SD. The numbers in parentheses are the numbers of rabbits.

$\S p<0.05$ in comparisons between control and vitamin E-deficient rabbits using Student's $t$ test.

Table 5. Distribution of radioiron $6 \mathrm{~h}$ after injection of transferrin-bound radioiron

\begin{tabular}{lcr}
\hline & $\begin{array}{c}\text { Control } \\
\text { (\% of total injected radioiron) }\end{array}$ & $\begin{array}{c}\text { Vitamin E- } \\
\text { deficient }\end{array}$ \\
\hline Thigh muscles* & $0.78 \pm 0.33(4) \dagger$ & $0.64 \pm 0.26(6)$ \\
Liver & $10.4 \pm 3.3(4)$ & $5.9 \pm 1.5(6) \ddagger$ \\
Spleen & $0.06 \pm 0.01(4)$ & $0.11 \pm 0.03(6)$ \\
Bone marrow (one femur) & $2.9 \pm 0.6(4)$ & $4.2 \pm 0.6(6) \ddagger$ \\
\hline * Total wet weight of thigh muscles: $20.5 \pm 2.4 \mathrm{~g}$ for control and 17.2 \\
$\pm 2.9 \mathrm{~g}$ for vitamin E-deficient rabbits. \\
$\ddagger$ Mean \pm SD. Numbers in parentheses are the numbers of rabbits. \\
$\ddagger p<0.05$ by Student's $t$ test.
\end{tabular}

This greater uptake by bone marrow is in agreement with previous ferrokinetic studies in vitamin E-deficient rabbits (2). At the 6-h interval, thigh muscles of vitamin E-deficient rabbits did not contain an excess of radioiron (Table 5). After 6 days, however, there was a significant excess of radioiron in thigh muscles of vitamin E-deficient rabbits in comparison to control rabbits (Table 6).

In the other radiotracer study, there was no uptake of heatdamaged erythrocytes, labeled with ${ }^{51} \mathrm{Cr}$, into skeletal muscle of control or vitamin E-deficient rabbits. This study was performed because vitamin $\mathrm{E}$ deficiency in certain species causes an exudative diathesis with hemorrhage into tissues (4).

Histologic studies. Sections of muscle from control rabbits bound the antiferritin antibodies minimally, and consequently they stained very scantily after incubation with a fluoresceintagged antibody to the antiferritin antibodies (Fig. 1A). The staining of skeletal muscle from vitamin E-deficient rabbits is illustrated in Figure $1 B$. There was little or no staining of muscle cells, but there was abundant staining of ferritin between the muscle cells, in areas where mononuclear cells were located (Fig. $1, B$ and $D$ ). There was no staining of muscle from vitamin Edeficient rabbits, however, when unimmunized guinea pig serum was used instead of antiferritin antibodies. The mononuclear cells also took the stain for nonspecific esterase (Fig. 1C), as would be expected of macrophages. Similar sections were stained for iron with potassium ferricyanide, but only in the most severely degenerated muscle was a small amount of stainable iron visible in a few mononuclear cells (not shown). The amount of stainable iron in these cells was greatly increased after parenteral treatment with iron (Fig. 1D).

Sections stained with hematoxylin and eosin showed extensive hyaline necrosis and infiltration of mononuclear cells in skeletal muscle from vitamin E-deficient rabbits. There was no hemorrhage, no erythrophagocytosis, and no phagocytosis of intravenously injected carbon particles by the mononuclear cells in skeletal muscle.
Table 6. Distribution of radioiron 6 days after injection of transferrin-bound radioiron*

\begin{tabular}{|c|c|c|}
\hline & \multicolumn{2}{|c|}{$\begin{array}{c}\text { Control deficient } \\
\text { (\% of total injected radioiron) }\end{array}$} \\
\hline Thigh muscles $\dagger$ & $0.28 \pm 0.07(4) \ddagger$ & $1.06 \pm 0.39(4) \S$ \\
\hline Liver & $15.33 \pm 2.79(4)$ & $6.23 \pm 1.39(4) \S$ \\
\hline Spleen & $0.19 \pm 0.04$ & $0.22 \pm 0.16(4)$ \\
\hline Bone marrow (one femur) & $0.71 \pm 0.11(4)$ & $0.60 \pm 0.10(4)$ \\
\hline \multicolumn{3}{|c|}{$\begin{array}{l}\text { * The initial weight of the rabbits was approximately } 1200 \mathrm{~g} \text {. } \\
\dagger \text { Total wet weight of thigh muscles: } 52.3 \pm 5.4 \mathrm{~g} \text { for control and } 40.1 \\
\pm 7.5 \mathrm{~g} \text { for vitamin E-deficient rabbits }(p<0.05) \text {. } \\
¥ \text { Mean } \pm \text { SD. The numbers in parentheses indicate the number of } \\
\text { abbits. } \\
\S p<0.01 \text { by Student's } t \text { test. }\end{array}$} \\
\hline
\end{tabular}

\section{DISCUSSION}

The data presented here are pertinent to four questions. What is the source of the excess iron in skeletal muscle of vitamin Edeficient rabbits? In what storage form is the iron sequestered? What cell types are involved? And, is sequestration due to increased uptake or decreased release? The source almost certainly is transferrin-bound iron since radioiron injected intravenously in this form accumulated in skeletal muscle and since there was no trapping of heat-damaged erythrocytes, no uptake of intravenously injected carbon particles, and no erythrophagocytosis in the muscles of vitamin E-deficient rabbits. It is even more certain that most of the sequestered iron is in the form of ferritin in macrophages since ferritin concentrations were so large and so localized to macrophages. Moreover, extra parenteral iron found its way to macrophages in skeletal muscle of vitamin Edeficient rabbits where it could be detected by staining with potassium ferricyanide.

In regard to the mechanism of iron sequestration, we found no evidence of increased uptake of transferrin-bound radioiron into muscle of vitamin E-deficient rabbits in short term (6-h) experiments. Long term (6-day) experiments, however, revealed an excess of radioiron in muscle of vitamin E-deficient in comparison with control rabbits. We interpret these results to mean decreased turnover of radioiron. Therefore, we conclude that reduced availability of iron for erythropoiesis in vitamin Edeficient rabbits (2) is due to slow release of iron from ferritin stored in macrophages in skeletal muscle.

Of the possible explanations of how vitamin E deficiency could impair iron release, the following two warrant consideration. (a) In the absence of vitamin E, a structurally abnormal ferritin might be produced. This possibility could explain the low ratio of soluble nonheme iron to radioimmunoassayable ferritin which we observed. However, it is more probable that the low ratio 

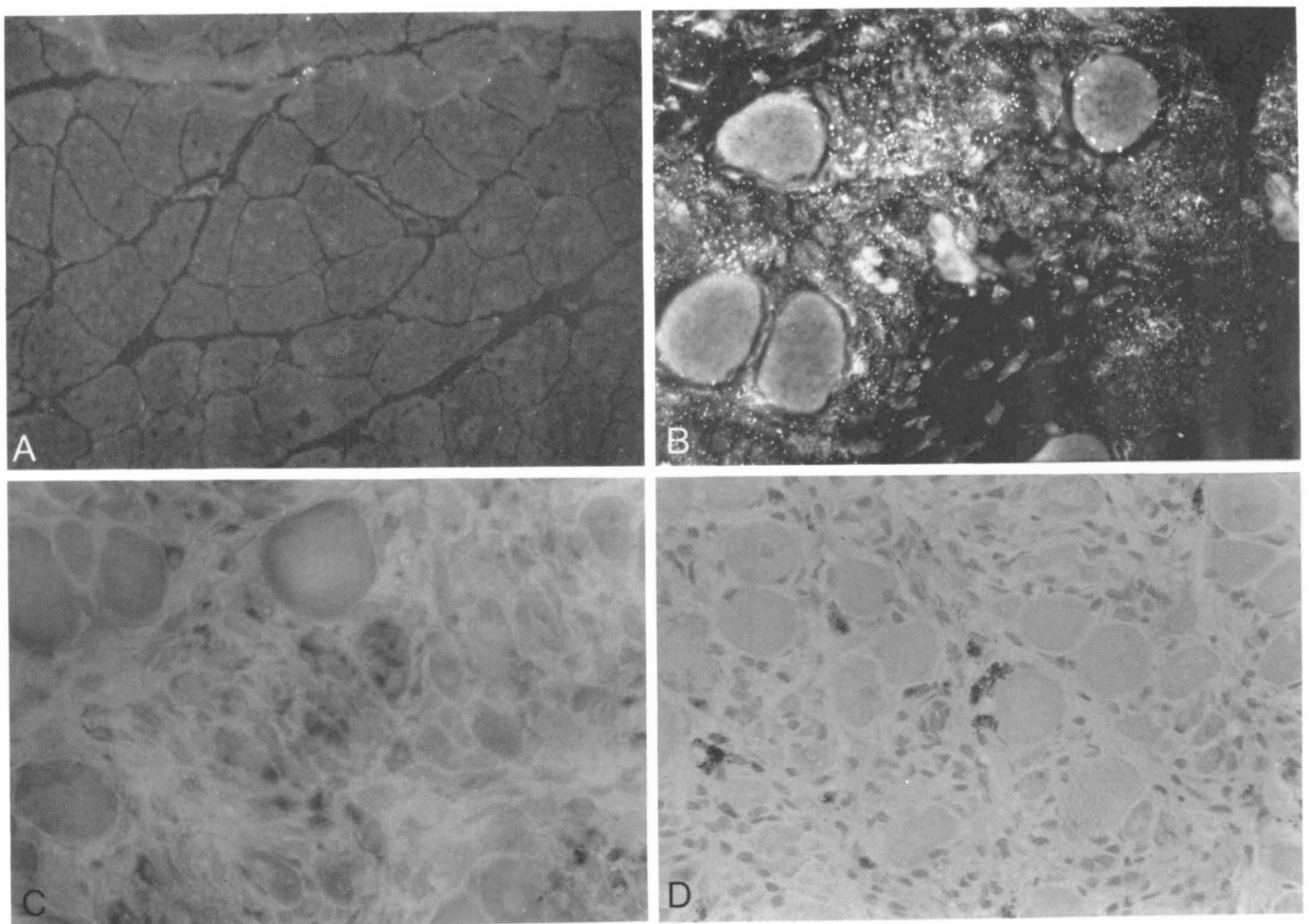

Fig. 1. $A$, immunohistological study of muscle ferritin of soleus muscle of control rabbits. Only scanty ferritin is detectable in normal muscle. $B$, immunohistological study of muscle ferritin of soleus muscle of vitamin E-deficient rabbits. Ferritin is absent in the intact myofibrils but abundant ferritin is present in the tissue between the myofibrils (infiltrating mononuclear cells) and the degenerating myofibrils. $C$, nonspecific esterase activity of soleus muscle of vitamin E-deficient rabbits. Dark staining of cytoplasm indicating enzyme activity is present in many mononuclear cells, especially those infiltrating the degenerating myofibrils. $D$, iron stain of soleus muscles of vitamin E-deficient rabbits receiving iron supplements. Abundant mononuclear cells are located between myofibrils. Stainable iron is present in many of these mononuclear cells.

reflects a difference in the number of macrophages, as our antibody detected ferritin in macrophages but not in normal muscle cells. (b) Vitamin E might be required for the release of iron from macrophages. It might function as a reducing agent directly interacting with ferritin, it might spare other reducing agents which facilitate the release of iron, or it might protect macrophages from oxidant damage. While none of these possible roles for vitamin $\mathrm{E}$ in iron release can be excluded, it is noteworthy that the response to vitamin $\mathrm{E}$ repletion provided no support for them. Indeed, vitamin E treatment for 3 days had no effect on the iron content of muscle of vitamin E-deficient rabbits.

Finally, since macrophages are known to be heterogeneous in their ability to recycle iron (5), it is possible that the population infiltrating necrotic muscle of vitamin E-deficient rabbits normally may not release iron readily. If such a population of macrophages were present, they would not be expected to respond to vitamin E repletion with a decrease in iron content. Until there is evidence to the contrary, therefore, it is reasonable to suggest that the abnormal iron metabolism of vitamin Edeficient rabbits is due to the presence in necrotic skeletal muscle of a large number of normally functioning macrophages.

\section{REFERENCES}

1. Adams RD (ed) 1975 Degenerative changes in muscle due to vitamin deficiency. In: Diseases of Muscle: A Study in Pathology, 3rd ed. Harper \& Row,
Hagerstown, MD, pp 182-187

2. Chou AC, Broun GO Jr, Fitch CD 1978 Abnormalities of iron metabolism and erythropoiesis in vitamin E-deficient rabbits. Blood 52:187

3. Cook JD 1970 An evaluation of adsorption methods for measurement of plasma iron-binding capacity. J Lab Clin Med 76:497

4. Creech BG, Feldman GL, Ferguson TM, Reid BL, Couch JR 1957 Exudative diathesis and vitamin E deficiency in turkey poults. J Nutr 62:83

5. Crosby WH 1982 Iron and the macrophage. The monocyte is a metabolic idiot. Arch Intern Med 142:233

6. Diehl JF 1959 Amino aciduria of E-avitaminosis. Exceptional role of glycine Proc Soc Exp Biol Med 100:657

7. Folin O 1914 On the determination of creatinine and creatine in urine. J Biol Chem 17:469

8. Gordon HH. Nitowsky HM. Cornblath M 1955 Studies of tocopherol deficiency in infants and children. I. Hemolysis of erythrocytes in hydrogen peroxide. Am J Dis Child 90:669

9. Greenwood FC, Hunter WM, Glover JS 1963 The preparation of ${ }^{131}$ I-labelled human growth hormone of high specific radioactivity. Biochem J 89:114

10. Hudson L, Hay FC 1980 Practical Immunology, 2nd ed. Blackwell Scientific Publications, Oxford, pp 233-237, 117-121

11. International Committee for Standardization in Hematology 1971 Proposed recommendations for measurement of serum iron in human blood. $\mathrm{Br} \mathrm{J}$ Haematol 20:451

12. Martinek RG 1964 Method for the determination of vitamin E (total tocopherols) in serum. Clin Chem 10:1078

13. Penders TJ, de Rooij-Dijk HH, Leijnse B 1968 Rapid isolation of ferritin by means of ultracentrifugation. Biochim Biophys Acta 168:588

14. Torrance JD, Bothwell TH 1968 A simple technique for measuring storage iron concentrations in formalinised liver samples. S Afr J Med Sci 33:9

15. Yam LT, Li CY, Crosby WH 1971 Cytochemical identification of monocytes and granulocytes. Am J Clin Pathol 55:283

16. Young JM, Dinning JS 1951 A relationship of vitamin E to nucleic acid metabolism. J Biol Chem 193:743 